\title{
156. Colony-Specificity in Compound Ascidians as Tested by Fusion Experiments
}

\section{(A Preliminary Report)}

\author{
By Hidemiti OKa and Hiroshi Watanabe \\ Zoological Institute, Tokyo Kyoiku University \\ (Comm. by Yô K. OKadA, M.J.A., Dec. 12, 1957)
}

Introduction. In Botryllus, a compound ascidian, the colony-specificity manifests itself among others as hindrance to fusion between two colonies. By fusion is meant the complete union of both test and vessels of one colony with the same organs in the other, regardless whether this occurs under natural conditions or is brought about by experimental means. In other words, the criterion for a fusion is the establishment of a common vascular system. ${ }^{1)}$

Bancroft ${ }^{21}$ was the first to take up the question of fusion in Botryllus. According to this author, unrelated colonies, such as are found next to each other in nature, do not fuse, whereas two pieces taken from the same colony always fuse completely. Sister and brother colonies, i.e. colonies developed from larvae extruded by the same colony, sometimes fuse and sometimes do not. That is all what Bancroft demonstrated by his experiments.

In re-examining and extending the fusion experiments of Bancroft, we have got some insight into the genetic control of the colony-specificity and the relation that exists between this and fertilization.

The investigation was carried out at the Shimoda Marine Biological Station. The materials used were living colonies of Botryllus primigenus reared on glass slides.

Fusion of colonies. 1) Two pieces taken from the same colony, ${ }^{33}$ when brought together, invariably fuse. Once two pieces were kept apart over the period of one year, but they at once, fused when brought together.

2) Colonies taken at random from nature in the majority of cases do not fuse. For instance, in a case 8 out of 10 colonies collected from an area of $1 \mathrm{~m}^{2}$ did not fuse with the standard colony also

1) Inasmuch as colonies or pieces thereof to be fused are capable of independent life, the fusion of colonies in Botryllus is to be compared with parabiosis in higher animals.

2) F. W. Bancroft: Variation and fusion of colonies in compound ascidians, Proc. California Acad. Sci., 3rd ser., 3, 137-186 (1903).

3) If a colony is cut in several pieces, the wounds heal very soon. In a day such pieces can not be distinguished from ordinary colonies. 
taken from that area.

3) Fusion is always possible between daughter colonies and the mother colony.

4) If two mature colonies are kept together in an aquarium, daughter colonies originated from each fuse with both colonies.

5) If more than three mature colonies are kept in an aquarium, daughter colonies originated from a colony fuse with one and only one more colony.

6) Sister colonies are sorted into four groups. Members of each group fuse with one another and with those of two other groups.

7) In case two mature colonies are kept in an aquarium, daughter colonies of the one colony sometimes fuse and sometimes do not with those of the other colony.

Self-incompatibility. Ascidians are hermaphrodites. So in compound ascidians a priori three ways of fertilization are possible, i.e. 1) fertilization within a single zooid, ${ }^{4}$ 2) between two zooids in a colony, ${ }^{5)}$ and 3 ) between two colonies.

By culturing mature colonies in aquaria, it has been demonstrated that 1) and 2) do not occur in Botryllus primigenus. In this species fertilization is possible only between different colonies. ${ }^{6)}$

What is interesting is the correlation between concrescibility (vegetative affinity) and fertilization (sexual affinity). Fertilization seems to be possible only between colonies which do not fuse.

To put it in the concrete, fertilization generally occurs between neighboring colonies such as are found in nature. On the contrary, fertilization never takes place between parental and filial colonies. Among these latter there appear four groups, within each of which fertilization is impossible, but between which fertilization is possible in definite combinations.

Experimental alteration of concrescibility. The concrescibility can be altered, though temporarily, by experimental means. For instance:

1) If two daughter colonies, between which fusion proved to be impossible, are fused each with a piece of the mother colony, and after a lapse of 24 hours again separated and brought together, they

4) This corresponds to self-fertilization in simple ascidians. Self-incompatibility is known in some forms of simple ascidians, notably Ciona.

5) This corresponds rather to self-fertilization than to cross-fertilization in simple ascidians, for all zooids in a colony are genetically identical, were it not for mutations.

6) True self-fertilization is impossible in Botryllus, for the ova must pass through several (asexual) generations before they are ready to be fertilized. However, a kind of self-fertilization in the sense that ova are fertilized by spermatozoa from the progeny of the zooid that produced these ova has been admitted for Botryllus by E. C. Herdman. Cf. E. C. Herdman: Botryllus, Liverpool Marine Biology Committee Memoirs, XXVI (1924), London. 
No. 10] Colony-Specificity in Compound Ascidians as Tested by Fusion Experiments 659

easily fuse. Thus two repulsive colonies can be made concresible through the mother colony.

2) On the other hand, if two daughter colonies, between which fusion proved to be feasible, are fused one with the one and the other with the other parental colony, and after a lapse of 24 hours again separated and brought together, they invariably refute fusion.

The above results are obtained only when the bringing together of the two colonies occurs immediately after separation from the parent colonies. In three or four days after separation the colonies return to the original state.

That the concrescibility of a colony can be altered temporarily by fusion with a definite partner perhaps implies that the substance or substances which determine this character are continuously produced in the body and carried by the blood stream.

Tentative interpretation. More study must be made before any genetical interpretation can be given, but for the present the following scheme seems to be the simplest possible way of summarizing the results.

The parent colonies each have two factors, $\mathrm{AB}$ and $\mathrm{CD}$ respectively, and produce two kinds of gametes. Thus there are formed four different combinations of factors in daughter generation, viz. $\mathrm{AC}, \mathrm{AD}$, $\mathrm{BC}$, and $\mathrm{BD}$. All the results obtained can be consistently explained, if the only assumption is made that two colonies fuse or refute fertilization, if they have at least one factor in common. ${ }^{\text {) }}$

It should not be taken as saying that concrescibility and selfincompatibility are necessarily both governed by the same factors. It only says that the one as well as the other can be explained by the same scheme. For explaining experimental alteration of concrescibility, of course, some additional assumption is needed.

7) These factors could be conceived as a series of alleles of a single gene like $\mathrm{S}$ gene in flowering plants. 